\title{
Sustainable urban mobility: the role of bus priority measures
}

\author{
S. Basbas \\ Department of Transportation and Hydraulic Engineering, \\ Faculty of Rural and Surveying Engineering, School of Technology, \\ Aristotle University of Thessaloniki, Greece
}

\begin{abstract}
It is well known that public transport plays an important role in sustainable urban mobility worldwide. This is the reason why local authorities have designed and implemented various priority measures in order to improve the performance of the public transport system and to promote its use in their areas. An efficient public transport system means less use of private passenger cars and it can lead to the overall improvement of the traffic and environmental conditions. Within the framework of this paper the role of bus priority measures in sustainable urban mobility is examined and presented. The reference area is the city of Thessaloniki, Greece and the bus priority measures examined and evaluated include with-flow and contra-flow bus lanes.

Keywords: sustainable mobility, bus transport priority measures, bus lanes.
\end{abstract}

\section{Introduction}

There are quite a lot of definitions concerning the sustainable transportation systems and sustainable mobility. An accurate definition for sustainable transportation systems originates from the European Union Council of Ministers of Transport. According to this definition, a sustainable transportation system is one that addresses the following issues [1]:

- Allows the basic access and development needs of individuals, companies and society to be met safely and in a manner consistent with human and ecosystem health, and promotes equity within and between successive generations. 
- Is affordable, operates fairly and efficiently, offers a choice of transport mode, and supports a competitive economy, as well as balanced regional development.

- Limits emissions and waste within the planet's ability to absorb them, uses renewable resources at or below their rates of generation, and uses non-renewable resources at or below the rates of development of renewable substitutes, while minimizing the impact on the use of land and the generation of noise.

Sustainable mobility is a term which can be defined in a number of different ways. According to the World Business Council for Sustainable Development [2] "sustainable mobility is the ability to meet the needs of society to move freely, gain access, communicate, trade, and establish relationships without sacrificing other essential human or ecological values today or in the future".

In June 2006 the European Commission issued a mid-term review of the 2001 Transport White Paper entitled "Keep Europe moving - Sustainable mobility for our continent". The use of the term "sustainable mobility" in the title of the review "serves to highlight a key dilemma of European transport policy, namely how to reconcile the free movement of people and goods, one of the basic pillars of the European Union, whilst at the same time protecting the environment and improving the health and safety of citizens" [3].

There are very important initiatives towards the direction of sustainable development and sustainable transportation systems. International organisations which are involved, one way or another, in this subject include Organisation for Economic Cooperation and Development (O.E.C.D.), European Community, European Conference of Ministers of Transport (E.C.M.T.), World Bank, World Business Council for Sustainable Development (W.B.C.S.D.) etc [4].

There have also been many efforts towards the dissemination of experiences concerning sustainable urban mobility. For example SMILE [5] aims to help local authorities cope with sustainable urban mobility by presenting good practices and introducing innovative approaches on a permanent basis. Organisations and projects dealing with sustainable mobility and urban environment issues at the European level can also be found at the European Mobility Week website [6].

Within the framework of this paper an attempt has been made to investigate the role of bus priority measures in urban transport mobility. The case study which is presented in the paper refers to the city of Thessaloniki, Greece and the bus priority measures examined and evaluated include with-flow and contra-flow bus lanes.

\section{Sustainable urban mobility and promotion of public transport}

The relation between public transport and sustainability is very significant. "There is a very strong link between public transport and sustainable 
development" said, among others, Wolfgang Meyer, International Association of Public Transport (UITP) President while opening the Conference "Towards sustainable urban transport in Europe: what actions are needed?” in 2004 [7].

The Council of European Municipalities and Regions (CEMR) response to the European Commission's public consultation on the mid-term review of the transport White Paper include, among other things, the following recommendation: "a new impetus and new measures to improve the share of more sustainable forms of transport in the modal split, notably through measures to promote public transport and limit the use of car (particularly in urban areas)" [8]. The UITP-EU Committee addressing specifically the issues of urban mobility in the European climate change and energy efficiency policies, strongly recommends the following actions [9]:

- $\quad$ strategy for modal shift and promotion of high quality public transport systems;

- $\quad$ european wide tax measures and road charging schemes;

- $\quad$ european-wide mandatory sustainable urban transport plans;

- $\quad$ european benchmarking to measure local and regional performance;

- $\quad$ european public awareness actions for behavioural change;

- $\quad$ investments in transport with priority in high energy efficiency and low Green House Gas (GHG) emissions.

From the above mentioned actions it becomes clear that the promotion of public transport is a necessity, and this includes the implementation of bus priority measures. Measures which could be part of a strategic local mobility plan (Ideas on Clean Infrastructure for Urban Transport) include the "construction/upgrading of public transport infrastructure for trams, metros and high quality bus networks (for example dedicated separated lanes)" [10].

According to the same source, "in the second half of 2007 the Commission will issue a Green Paper on urban transport to launch a debate on potential European added value to action at the local level". Sometimes the impact of bus priority measures to the road network conditions is less than expected. Transportation Research Group in the University of Southampton, UK, carried out a research on the role of strong bus priority measures, involving capacity reallocation to buses, using traffic signalling and/or physical measures, in sustainable urban transport [11].

\section{Bus priority measures}

Bus priority measures have been the subject of many research efforts worldwide. The benefits from the implementation of bus priority measures include reduced bus passengers' journey time, improved bus regularity, increased bus patronage for the operator, changes in modal split in favor of public transport and overall improvement of the environmental conditions and the quality of life.

Bus priority measures, based on a series of case studies in UK [12] can be grouped as follows: 
- with-flow and contra-flow bus lanes;

- bus gates and rising bollards;

- $\quad$ guided busways;

- $\quad$ pre-signals and bus advanced areas, Selective Vehicle Detection (SVD), MOVA, busSCOOT, Automatic Vehicle Location (AVL);

- $\quad$ mixed priority streets and bus friendly traffic calming (green);

- $\quad$ high Occupancy Vehicle (HOV) lanes and no-car lanes;

- bus Park and Ride;

- complementary measures.

With-flow bus lanes and contra-flow bus lanes are the lanes restricted to buses (but other road users like drivers of high occupancy vehicles (HOV), emergency vehicles etc. are possibly entitled to use these lanes). It must be mentioned at this point that with-flow lanes is the most traditional bus priority measure worldwide. Bus gates and rising bollards tend to be considered when access to a particular street is to be restricted to buses while guided busways travel on their own tracks [12]. A pre-signal "aims to give buses priority access into a bus advanced area of the main junction stop line so as to avoid the traffic queue and reduce bus delay at the signal controlled junction" [13].

Bus detectors are necessary in order to maximize the benefits from the use of pre-signals. The London experience from the implementation of the project iBUS (use of GPS technology in the application of SVD) showed that there are many benefits in terms, among other things, of average journey time savings/bus/junction and average delay savings [14].

Bus-based Park and Ride combine private car trips and trips made by bus. There is of course the question whether such schemes actually meet their objective about the reduction of traffic in the areas where they are implemented. The examination of eight case studies in UK has shown that "the main effect of the schemes is traffic redistribution and that their role within traffic restraint policies is unlikely to be directly one of traffic reduction" [15].

Intermittent Bus Lanes (IBL) are the lanes in which the status of a given section changes according to the presence or not of a bus in its spatial domain and unlikely dedicated bus lanes, IBL do not significantly reduce street capacity $[16,17]$.

Various EU research project deal with the concept of bus priority measures. The project PRISCILLA (Bus Priority Strategies and Impacts Scenarios Developed On A Large Urban Area) aimed at the facilitation of the rapid take-up of experiences and know-how gained in the previous RTD projects related to bus priority systems concerning single junctions or bus priority- corridors and gather still missing knowledge on effects and impacts in wide networks (100-300 buses, 80-130 intersections, city centre and suburbs) [18].

Bus priority schemes were examined, among other measures, in the framework of the project LEDA. The main objective of the project LEDA (Legal and Regulatory Measures for Sustainable Transport in Cities) was to promote sustainability in urban transport by means of legal and regulatory measures [19]. 


\section{Examination of with-flow and contra-flow bus lanes in the city of Thessaloniki}

\subsection{Presentation of the Thessaloniki public transport system}

Thessaloniki is the second biggest city in Greece, it is situated in the north part of the country and has a population of around one million inhabitants. A number of 1.600 .00 trips were made in 1998 on a daily basis in the city with all transport modes (compared to 1.350 .000 in the year 1988) of which 400.000 trips had at least one end in the city center [20,21]. The car ownership (number of passenger cars per 1.000 inhabitants) varies between 220 and 305 with an average value of 253, while ten years before the respective value was 177 . The city is characterized by serious traffic and associated environmental problems especially in its centre.

Nowadays the public transport system in the city consists only from buses. The Thessaloniki Bus Operator (O.A.S.Th.) has a total number of 583 buses (of which 279 are articulated) [22]. There are 72 bus lines carrying around 150 million passengers per year (that means around 12.500 .000 passengers/month or 411.000 passengers/day). It is also important to mention at this point that a metro system is under construction in the city central area. The technical characteristics of this system are as follows: basic line with a length of 9,6 km. (two tunnels, single track), 13 stations, designed capacity of 18.000 passengers/hour/direction, estimated number of passengers equal to 250.000/day) [23]. The first line of 9,6 $\mathrm{km}$.length is expected to finish by the year 2012. Two other lines are also foreseen in the long term: the first line will have a length of 5,8 km. and it will serve the western part of the city and the second line will have a length of $5 \mathrm{~km}$. and will serve the eastern part of the city. The estimated cost of the basic line is 1.060 million $€$ while the cost for the additional two lines is estimated to be 1.100 million $€$.

\subsection{Examination of the with-flow bus lanes in Thessaloniki}

The need to promote the city public transport system through the implementation of bus lanes was realized in the framework of a study concerning the redesign of the bus network in the city. The specific study was carried out in 1987. Today, there are four with-flow bus lanes in the city, three of which are found in the central area. The road axes where these three with-flow bus lanes are implemented are presented in the following Figure 1.

The first with-flow bus lane was implemented in the Mitropoleos Rd. (oneway street in the city centre) and has a length of $980 \mathrm{~m}$. Table 1 presents the bus average speed before and after the implementation of the with-flow bus lane. The results show a very significant increase in bus speed during the first period after the implementation of the bus lane. The violation of the bus lane by private passenger cars and taxi in the next years (1991-1997) led to the reduction of the bus average speed, as shown in Table 1, but benefits still remain when the situation is compared to the one before the implementation of the bus lane. 


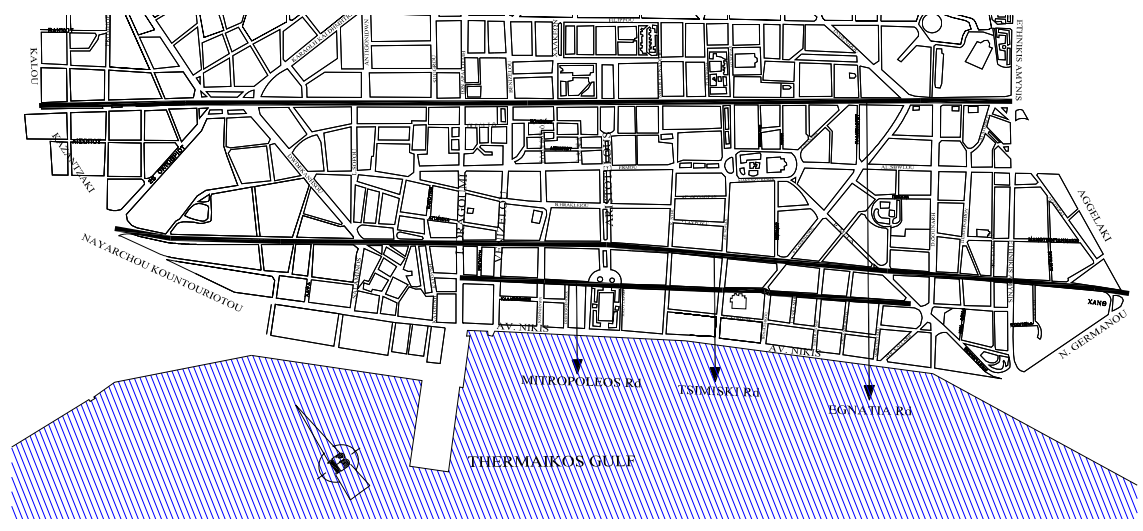

Figure 1: Road axes with with-flow bus lanes in the central area of Thessaloniki.

Table 1: $\quad$ Speed of buses in the with-flow bus lane of Mitropoleos Rd.

\begin{tabular}{|l|c|c|c|}
\hline \multirow{2}{*}{$\begin{array}{l}\text { Bus lane } \\
\text { section } \\
\text { under } \\
\text { study }\end{array}$} & $\begin{array}{c}|c| \\
\text { "Bus average speed (km/h) }\end{array}$ & Bus average speed (km/h) \\
\cline { 2 - 4 } & situation & $\begin{array}{c}\text { "After" } \\
\text { situation } \\
\text { (year 1991) }\end{array}$ & $\begin{array}{c}\text { "After" situation } \\
\text { (year 1997) compared to } \\
\text { year 1991 }\end{array}$ \\
\hline $\begin{array}{l}\text { Between bus stops } \\
\text { "Venizelou" and } \\
\text { "Aristotelous" }\end{array}$ & 7,9 & 25,21 & 18,2 \\
\hline $\begin{array}{l}\text { Between bus stops } \\
\text { "Aristotelous" and } \\
\text { "Mitropoli" }\end{array}$ & 16,3 & 24,34 & 20,4 \\
\hline $\begin{array}{l}\text { Between bus stops } \\
\text { "Mitropoli" and } \\
\text { "Diagonios" }\end{array}$ & 9,5 & 17,93 & 14,0 \\
\hline
\end{tabular}

Source: [24].

The second with-flow bus lane was implemented in Vas.Olgas Rd. (one way street) in 1992. This road connects the eastern part of the city with the central area. Initially it had a total length of $3.200 \mathrm{~m}$. and recently (2nd half of 2006) it has been extended towards its eastern part. The evaluation results show that there has been a reduction in the values of buses' average travel time (around 10-15\%) during the morning peak period [24]. In 1996 a third with-flow bus lane was implemented in the central area, and more especially in the Tsimiski Rd. (one way street). The length of the third bus lane is $1.300 \mathrm{~m}$. As expected, there was again a significant reduction in the values of buses' average travel time after 
the implementation of the with-flow bus lane (e.g., YMCA bus stop to P.Dikastiria bus stop: bus average travel time was reduced to $69,4 \mathrm{sec}$. from 99,7 in the previous situation - year 1996 measurements) [24]. The last with-flow bus lane was implemented in Egnatia Rd-Monastiriou Rd axis. (city centre) and has a length of $1750 \mathrm{~m}$. (This axis is a two-way street).

During the period 1988-1998 there was an increase in the number of people who believed that the level of service of the public transport system of the city is satisfactory or quite satisfactory. At the same time, the percentage of people using buses is decreased. It seems that bus priority measures introduced in the city during that period did not seriously affect modal split in favor of public transport [25].

According to another research in Thessaloniki [26] it was found that $41 \%$ of the people in the city (results are based on a questionnaire survey - 418 interviews, year 2000) believe that they use buses "more" than before the bus lanes, $3 \%$ believe they use buses "less" and $56 \%$ believe they use the buses "the same". It is also important to notice that, according to the same research, $51 \%$ believe that the impact of bus lanes to the rest traffic is "little", $38 \%$ "important" and $11 \%$ "none". Finally, the vast majority $(72 \%)$ believe that the bus lane network should expand, when only $7 \%$ believe the opposite and $21 \%$ are neutral.

The evaluation of the environmental impacts of the bus lane along Egnatia Rd. through the use of the traffic simulation model SATURN (Simulation and Assignment of Traffic to Urban Road Networks) gave the following results [27]: changes in the level of emissions of $\mathrm{CO}, \mathrm{CO}_{2}, \mathrm{NOx}, \mathrm{HC}$ and $\mathrm{Pb}$ cannot be easily identified when considering the total area of the city centre. On the contrary, results have shown that there has been a substantial decrease of $\mathrm{CO}$ and $\mathrm{CO}_{2}$ emissions in the near area of the examined bus lane, for both morning and afternoon peak period. NOx and $\mathrm{HC}$ emissions have been reduced only during the afternoon peak period.

It is also important to mention at this point that future plans include the implementation of additional with-flow bus lanes in the city [28]. The results from the examination of future bus lanes have shown [29,30] that their implementation is expected to produce an average reduction of $11 \%$ in $\mathrm{CO}$ emissions, $5 \%$ in NOx emissions and $9 \%$ in $\mathrm{HC}$ emissions in the streets, where the bus lanes will be implemented. The $\mathrm{CO}$ emissions reduction after the implementation of bus lanes constitutes in average the $21 \%$ of the total reduction of $\mathrm{CO}$ emissions expected after the implementation of various under study/construction major transport infrastructure projects in Thessaloniki (e.g., metro system, submerged tunnel). Similarly, NOx and VOC - HC emissions reduction due to bus lanes constitutes in average the $7 \%$ and $23 \%$, respectively, of the reduction expected by all the under study/construction major transport infrastructure projects. It must be mentioned at this point that ex-ante, on-going and ex-post evaluation should be carried out in order to obtain a clear view of the impact of the bus lanes [31].

Photographs of the existing with-flow bus lane network in the city of Thessaloniki are presented in Figure 2. 


\subsection{Examination of the under study contra-flow bus lane in Thessaloniki}

The case concerning the implementation of a contra-flow bus lane in the central area of Thessaloniki was examined in the framework of a research carried out in the Faculty of Rural and Surveying Engineering, Department of Transportation and Hydraulic Engineering, Aristotle University of Thessaloniki [32]. The objective of the research was to assess the traffic and environmental impacts of the contra-flow bus lane along Tsimiski Rd. The evaluation was made through the use of the traffic simulation model SATURN. In the framework of the specific research various indicators such as average speed, delays, travel time as well as energy consumption and pollutants emitted $\left(\mathrm{HC}, \mathrm{CO}_{2}, \mathrm{CO}, \mathrm{NOx}, \mathrm{Pb}\right)$ are examined.
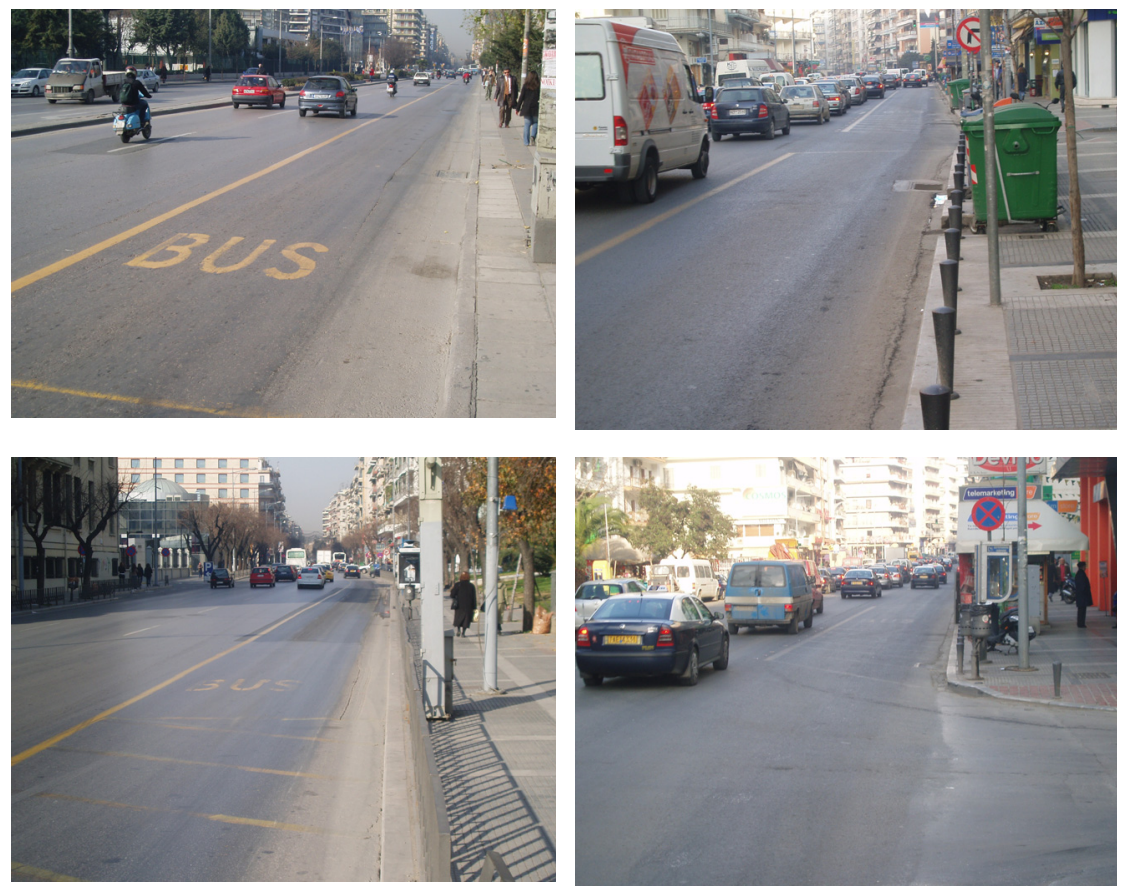

Figure 2: With-flow bus lanes in the Thessaloniki city network.

Values of the indicators examined for the "before" and "after" situation for the peak hour are presented in Tables 2 and 3 respectively.

It must also be mentioned at this point that the Hellenic Institute of Transport carried out a feasibility study [33] concerning the implementation of a contraflow bus lane in the Vas.Olgas Rd, (eastern part of Thessaloniki) in 2003 and the project was proved to be justified. 
Table 2: $\quad$ Indicators in the "before" and "after" situation (peak hour).

\begin{tabular}{|c|c|c|c|}
\hline & $\begin{array}{c}\text { "Before" } \\
\text { situation }\end{array}$ & $\begin{array}{c}\text { "After" } \\
\text { situation }\end{array}$ & $\begin{array}{c}\text { Difference } \\
\text { (\%) }\end{array}$ \\
\hline \multicolumn{2}{|c|}{ Values of indicators for all types of vehicles } \\
\hline Average speed (km/h) & 9,3 & 9,7 & 4,12 \\
\hline Delays (pcu*hrs) & 12036,5 & 11283,5 & $-6,67$ \\
\hline Travel time (pcu*hrs) & 18011,18 & 17353,5 & $-3,79$ \\
\hline Fuel consumption (lit) & 46907,6 & 46138,5 & $-1,67$ \\
\hline \multicolumn{2}{|c|}{ Values of indicators for buses } \\
\hline Average speed (km/h) & 12,8 & 12,0 & $-6,67$ \\
\hline Travel distance (pcu*kms) & 357,4 & 399,7 & 10,58 \\
\hline Travel time (pcu*hrs) & 187,9 & 216,6 & 13,25 \\
\hline Fuel consumption (lit) & 990,6 & 1071,7 & 7,57 \\
\hline
\end{tabular}

Table 3: Values of $\mathrm{HC}, \mathrm{CO}_{2}, \mathrm{CO}, \mathrm{NOx}, \mathrm{Pb}$ in the "before" and "after" situation.

\begin{tabular}{|c|c|c|c|}
\hline & $\begin{array}{c}\text { "Before" } \\
\text { situation }\end{array}$ & $\begin{array}{c}\text { "After" } \\
\text { situation }\end{array}$ & $\begin{array}{c}\text { Difference } \\
(\%)\end{array}$ \\
\hline \multicolumn{4}{|c|}{ Values of indicators for all types of vehicles } \\
\hline $\mathrm{HC}(\mathrm{Kg})$ & 554,83 & 565,38 & 1,87 \\
\hline $\mathrm{CO}_{2}(\mathrm{Kg})$ & 25795,99 & 26239,31 & 1,69 \\
\hline $\mathrm{CO}(\mathrm{Kg})$ & 3185,63 & 3247,75 & 1,91 \\
\hline $\mathrm{NOx}(\mathrm{Kg})$ & 445,34 & 450,19 & 1,08 \\
\hline $\mathrm{Pb}(\mathrm{Kg})$ & 2,64 & 2,68 & 1,49 \\
\hline \multicolumn{4}{|r}{}
\end{tabular}

\section{Discussion}

Sustainable mobility plays an important role in the formation of transport policy worldwide and in European Union in particular. The use of the term "sustainable mobility" in the title of the mid-term review of the 2001 Transport White Paper shows the importance of this issue for the European Union for the forthcoming years. The relation between public transport and sustainability is also proved to be very significant. The promotion of public transport in urban areas is based, among other things, on bus priority measures. The benefits from the implementation of bus priority measures are very important in terms of sustainable mobility since the use of public transport means fewer environmental problems (in terms of emissions and energy consumption), more people on buses and fewer people in private passenger cars, a safer environment and an overall improved level of quality of life. There are a variety of bus priority measures. The most commonly applied measure is the with-flow bus lane but new technologies (i.e. ITS), and especially the use of GPS technology, provide advanced solutions in the road network. The examination of with-flow bus lanes in the city of Thessaloniki showed that there are important benefits in terms of increased speed of buses (at least during the first period of their implementation, 
because afterwards the violation of bus lanes by other road users actually lead to lower speed). Evaluation results have shown that there is a substantial decrease of $\mathrm{CO}$ and $\mathrm{CO}_{2}$ emissions in the near area of the Egnatia bus lanes, for both morning and afternoon peak period. $\mathrm{NOx}$ and $\mathrm{HC}$ emissions have been reduced only during the afternoon peak period. $\mathrm{CO}$, NOx and $\mathrm{VOC}-\mathrm{HC}$ emissions after the implementation of new with-flow bus lanes constitutes in average the $21 \%$, $7 \%$ and $23 \%$, respectively, of the reduction expected by all the under study/construction major transport infrastructure projects in the city. The evaluation of the contra-flow bus lane showed that the values of $\mathrm{HC}, \mathrm{CO}_{2}, \mathrm{CO}$, $\mathrm{NOx}, \mathrm{Pb}$ in the "before" and "after" situation for all types of vehicles remain almost the same. Fuel consumption for buses was increased and this can be partially explained by the fact that buses travel longer distance in the "after" situation due to the necessary changes in their routes.

\section{References}

[1] Shepherd, S.P., Zhang, X., Emberger G., Hudson, M., May, A.D. \& Paulley, N. Design Optimal Urban Transport Strategies: The Role of Individual Policy Instruments and the Impact of Financial Constraints, Transport Policy, 13, pp. 49-65, 2006.

[2] Massachusetts Institute of Technology and Charles River Associated Incorporated, Mobility 2001-world mobility at the end of the twentieth century and its sustainability, Sustainable Mobility Working Group of the World Business Council for Sustainable Development, 2001, www.wbcsdmobility.org

[3] Stead, D., Mid-term review of the European Commission's 2001 Transport White Paper, EJTIR, 6, no.4 (2006), pp.365-370.

[4] Pitsiava-Latinopoulou, M., Basbas, S., \& Christopoulou, P., Sustainable Transport Systems: Trends and Policies, Proc. of the 12th Int. Conf. On Urban Transport and the Environment in the 21st Century, eds. C.A. Brebbia \& V. Dolezel, WIT Press, International Series: WIT Transactions on The Built Environment, Vol 89, pp. 13-22, 2006.

[5] SMILE, The Gateway to Sustainable Mobility, www.smile-europe.org

[6] European Mobility Week, www.mobilityweek-europe.org

[7] International Association of Public Transport (UITP), http://www.uitp.com

[8] CEMR response to the European Commission's public consultation on the mid-term review of the Transport White Paper, 2006, www.ccre.org

[9] UIPT, European Union, The role of public transport to reduce Green House Gas emissions and improve energy efficiency, Position on the European Climate Change Programme and the Green Paper on Energy Efficiency, Position Paper, March 2006.

[10] Kopanezou, E., Urban transport and Cohesion Policy, Brussels, 2006.

[11] Houncell, N.B, Schoon J.G., Rajbhandari, B. \& Waterson, B.J., The role of strong bus priority measures in Sustainable Urban Transport, 
Transportation Research Group, School of Civil Engineering and the Environment, University of Southampton, UK, 2002.

[12] Department for Transport, Bus Priority - The Way Ahead, Resource Pack, Edition 2, UK, 2004.

[13] Wu, J. \& Hounsell, N., Bus priority using pre-signals. Transportation Research Part A: Policy and Practice, 32(8), pp. 563-583, 1998.

[14] Bus Priority Team, Transport for London, Bus priority at traffic signals keeps London's buses moving - Selective Vehicle Detection (SVD), 2006.

[15] Parkhurst, G., Influence of bus-based park and ride facilities on users' car traffic. Transport Policy, 7, pp.159-172, 2000.

[16] Viegas, J. \& Lu, B., The Intermittent Bus Lane signals setting within an area. Transportation Research-Part C, 12, pp.453-469, 2004.

[17] Eichler, M. \& Daganzo, C.F., Bus lanes with intermittent priority: Strategy formulae and an evaluation, Transportation Research-Part B, 40, pp.731-744, 2006.

[18] Project PRISCILLA (Bus Priority Strategies and Impact Scenarios Developed On A Large Urban Area), 2000-2002, Project funded by the European Community under the "Information society Technologies" Programme, FP5, www.trg.soton.ac.uk/priscillla

[19] Project LEDA (Legal and Regulatory Measures for Sustainable Transport in Cities), 1998-1999, Project funded by the European Community under the Transport RTD Programme, Research For Sustainable Mobility, http://cordis.europa.eu

[20] Laboratory of Transport Engineering, Civil Engineering Department, Aristotle University of Thessaloniki, Research on trip characteristics in Thessaloniki Metropolitan Area, Thessaloniki, 1989.

[21] Trademco, Denco, Aggelidis, Truth, Infodim, SDG, WS-Atkins, General Transportation Study of Thessaloniki Metropolitan Area, Thessaloniki, 1998.

[22] Urban Transport Organisation of Thessaloniki (OASTH), www.oasth.gr

[23] Attiko Metro S.A., www.ametro.gr

[24] Transport \& Organisation Section, Civil Engineering Department, Aristotle University of Thessaloniki, Evaluation and investigation of potentiality for the extension of bus lanes system in Thessaloniki, Final Report, 1997.

[25] Basbas, S., Evaluation of bus transfer stations from the passenger's point of view. Proc. of the 12th Int. Conf. On Urban Transport and the Environment in the 21st Century, eds. C.A. Brebbia \& V. Dolezel, WIT Press, International Series: WIT Transactions on The Built Environment, Vol 89, pp. 73-82, 2006.

[26] Zacharaki, E., The effects of bus lanes in the city of Thessaloniki (case study), Master Thesis, Supervisor: Goodwin, P., University of London, Centre for Transport Studies, Imperial College, University College, Intercollegiate MSc Course in Transport, 2000. 
[27] Basbas S., Evaluation of bus lanes in central urban areas through the use of modeling techniques, Proc. of the $10^{\text {th }}$ Int. Conf. On Urban Transport and the Environment in the 21st Century, eds. C.A. Brebbia \& L.C. Wadhwa, WIT Press, International Series on Advances in Transport, pp. 389-397, 2004.

[28] Grigoriadou M., Natsinas T. \& Papaioannou P., Feasibility \& implementation study for bus lanes (with flow \& contra flow) along major road axes in Thessaloniki Metropolitan Area, Phase B' Report, Thessaloniki, 2003.

[29] Basbas S., Nikolaou K., Environmental and traffic evaluation of bus lanes, Proc. of the 5th Int. Conf. On Environmental Technology (Heleco'05), Athens, 2005.

[30] Nikolaou, K., Toskas, G., Natsinas, T., Grigoriadou, M. \& Basbas, S., Bus lanes and vehicle emission reduction in urban areas, Proc. of the Protection and Restoration of the Environment VII, eds. C. Moutzouris, C. Christodulatos, D. Dermatas, A. Koutsospyros, C. Skanavis \& A. Stamou, associated eds. W. Braida, Z. Skoula \& V. Tsoukala, Mykonos, 2004.

[31] Bouki, A., Evaluation system for the operation of bus lanes: Methodology and implementation in terms of external productivity, Master Thesis, Supervisor: Taxiltaris C., M.Sc. Course on Design, Organisation and Management of Transport Systems, Aristotle University of Thessaloniki, 2005.

[32] Ligas, I. \& Massias, D., Traffic and environmental evaluation of bus lanes with the use of SATURN, Diploma Thesis, Supervisor: Basbas, S., Department of Transportation and Hydraulic Engineering, Faculty of Rural and Surveying Engineering, Aristotle University of Thessaloniki, 2006.

[33] Hellenic Institute of Transport (HIT), Feasibility study for the implementation of a contra-flow bus lane in the Vas.Olgas Rd. together with the reversion of the direction of two lanes of general traffic in the sea-cost avenue, Final Report, 2003. 